\section{A (des)legitimação da Libras em práticas discursivas online}

The (de)legitimation of the Libras in online discursive practices

Jubileia Mendes de Matos COELHO (UFMT) jubileia_matos@hotmail.com

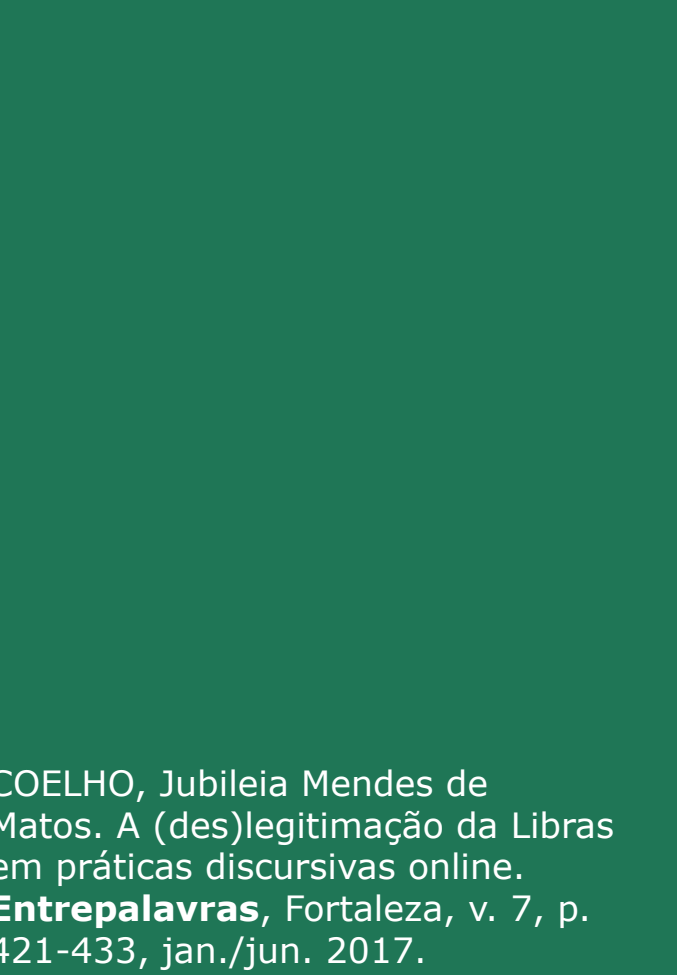

Resumo: Este trabalho propõe analisar sete comentários veiculados no blog "Chongas" sobre a falta de competência linguística do surdo. A questão que orienta a pesquisa é: Como práticas discursivas podem contribuir para a (des) legitimação da Libras? Teoricamente, este trabalho baseia-se nos conceitos de Habitus, Competência Linguística e Língua Legítima, de Bourdieu (2004, 2008). A partir desses conceitos, destaca-se que a Língua Brasileira de Sinais, Libras, apesar de ser considerada como segunda língua oficial do Brasil, se mantém em uma relação subalterna em determinados discursos, fato evidenciado tanto nos excertos que a deslegitimam, quanto na necessidade de enunciar sua legitimidade como língua na modalidade gestual-visual. Com base na contribuição de Bourdieu, buscase romper com práticas discursivas de exclusão e propor a legitimação da Língua de Sinais (modalidade gestualvisual) e o reconhecimento das diferenças linguísticas. Como resultado, pode-se observar que, nas práticas discursivas online, o habitus é considerado como um conjunto de práticas adquiridas nas interações e incorporadas às outras práticas sociais que formam o Capital 
v. 7 (1)

421-433

jan/jun

2017

Cultural do enunciador ou falante. No entanto, as posições não são neutras, mas permeadas por relações de poder evidenciadas nas práticas discursivas online.

Palavras-chave: Competência linguística. Língua legítima. Libras.

Abstract: This paper aims at analysing seven comments published on the blog "Chongas", about the lack of linguistic competence of the deaf persons. The question that triggered this research was: How can discursive practices contribute to both delegitimization and legitimation of Libras? Theoretically, this paper is based on Bourdieu's concepts of Habitus, Linguistic Competence and Legitimate Language (2004, 2008). From these concepts, it is evident that the Brazilian Language of Signs, Libras, although considered as the second official language of Brazil, still remains in a subaltern relation in certain speeches, as both in excerpts that delegitimize it and in the need of declaring its legitimacy as a language of gestural-visual modality. Thus, with this theoretical support, it is proposed both to break off with exclusionary discursive practices and to establish the legitimation of the sign language, in the gestural-visual modality, and the awareness of the linguistic difference. As a result, it was observed that, in the online discursive practices, the habitus is considered as a set of practices acquired in the social interactions and incorporated to the other social practices that compound the Cultural Capital of the enunciator, the speaker. As a conclusion, it is evident that discursive practices are never neutral, but always permeated by power relations.

Keywords: Linguistic competence. Legitimate language. Libras.

\section{Introdução}

As pesquisas sobre a pessoa surda (MAZZOTTA, 2011; PERLIN, G.; STROBEL, 2014; QUADROS, 2008; SKLIAR, 2005) abordam aspectos históricos e relatam a condição social, cultural e linguística imposta ao sujeito surdo, de negação da Língua Brasileira de Sinais - Libras, em práticas discursivas e sociais. Sendo necessário, inclusive, enunciar essa legitimação em razão de discursos que a deslegitimam. A Lei $n^{\circ}$ 10.436 de 24 de abril de 2002, em seu parágrafo único, define a Língua Brasileira de Sinais - Libras como forma de comunicação e expressão com estrutura gramatical própria que constitui um sistema linguístico de comunicação, transmissão de ideias e fatos, oriundos de comunidades de pessoas surdas do Brasil. Diante deste quadro, o discurso da deslegitimação da Língua de Sinais implica, supostamente, que a pessoa surda seja desprovida de uma competência linguística, acionando, dessa forma, uma língua legítima como produtora do referencial linguístico de uma suposta competência do falante na modalidade oral-auditiva padrão (Língua Portuguesa) em detrimento da modalidade gestualvisual (Libras). Daí, a importância de discutir como práticas discursivas podem contribuir para a (des) legitimação da Libras em discursos vinculados à "deficiência" e à competência linguística do sujeito surdo, 
como iremos retratar neste texto. A concepção de "deficiência" parece estar atrelada à competência linguística e, por sua vez, vinculada à noção de "mercado linguístico". Sabendo-se que o valor de mercado é dado à língua valorizada socialmente (BOURDIEU, 2008, p.42), a língua considerada legítima e de valor social no Brasil é a norma culta da Língua Portuguesa.

Com base nessas premissas, os conceitos de habitus, Competência Linguística, Língua legítima são tomados, aqui, em relação à Libras e à competência linguística do surdo, para buscar entender como as posições discursivas dos enunciadores ocorrem nos enunciados.

Bourdieu (2004) afirma que os enunciadores são agentes que "investem os princípios incorporados de um habitus gerador: um sistema de disposições (...) com a diferença de que se trata de disposições adquiridas pela experiência, logo, variáveis segundo o lugar e o momento" (BOURDIEU, 2004, p.21). Esse conceito vem em oposição a simples execução de uma prática (BOURDIEU, 2004, p.21), conforme o Estruturalismo de Saussure (2006) e se aproxima do conceito de Gramática Gerativa de Chomsky (1980), especificamente nas "capacidades geradoras das disposições", as quais, "trata de disposições adquiridas, socialmente constituídas" (BOURDIEU, 2004, p.21). Porém, diferentemente do Chomsky (1980), para Bourdieu as disposições são adquiridas pela experiência, no decorrer das práticas sociais.

Sendo assim, a noção de agente social está atrelada ao habitus como capacidade de gerar determinadas disposições adquiridas socialmente em vivências práticas, podendo, assim, determinar e pré-estabelecer posicionamentos discursivos. Para Bourdieu (2004), o agente social não é o sujeito, o autor entende que as "disposições adquiridas" se dão de dentro para fora, a partir do habitus incorporados aos indivíduos.

\section{O habitus em relação ao sujeito}

Neste trabalho, entende-se que o habitus, disposições adquiridas pela experiência e incorporadas aos indivíduos pelas práticas sociais (BOURDIEU, 2004, p.21), formam o capital desse sujeito, contudo, essas práticas e vivências são permeadas por relações de poder. Para entender como ocorre a (des)legitimação da Libras em enunciados, é necessário recorrer às noções de sujeito, enunciado e discurso. Nesse sentido, pondera-se que o sujeito, por ser disperso, assume posições discursivas ao enunciar (FOUCAULT, 2008). 
v. 7 (1)

421-433

jan/jun

2017

Foucault (2008, p.16) esclarece que o enunciado não existe sozinho, mas é produzido no interior de práticas discursivas e se constitui em um momento histórico determinado, no qual apresenta sentido e remete a outros enunciados, outros "já ditos". Ainda, segundo o autor, o sujeito se constitui em um sujeito disperso, ocupando uma posição, quando profere um ato de enunciação. Desse modo, a enunciação pode ser um ato isolado, já o enunciado, possui uma materialidade repetível em condições específicas.

Entendendo a questão do sujeito, uma segunda questão a ganhar atenção nesse trabalho remete ao reconhecimento do habitus como orientador de posições a serem ocupadas a partir das experiências oriundas das práticas sociais. Assim, o seu capital econômico, cultural, social também interferem no posicionamento assumido pelo sujeito.

Contudo, ao entender o sujeito como disperso, enfatiza-se que o discurso não é neutro, mas político, cultural e histórico e se reporta a outros já-ditos ou que serão ditos (FOUCAULT, 2008). Um habitus familiar ou de classe, por exemplo, pode orientar uma futura posição discursiva e prática social, sendo que, "esse sistema de disposições incorporado pelo sujeito não o conduz em suas ações de modo mecânico", rígido. Ao contrário, o habitus (familiar, classe, cultural) funciona como orientador de um possível posicionamento do sujeito, embasado pelas experiências adquiridas em determinado "campo", social, econômico, cultural", desde que "adaptados pelo sujeito às variadas circunstâncias de ação" (NOGUEIRA; NOGUEIRA, 2002, p.20). Ainda segundo as observações dos autores o "ator da Sociologia da Educação de Bourdieu não é nem o indivíduo isolado, consciente, reflexivo, nem o sujeito determinado, mecanicamente submetido às condições objetivas em que ele age" (NOGUEIRA; NOGUEIRA, 2002, p. 20-21).

Assim, o Conhecimento, o Reconhecimento e o Desconhecimento de um determinado capital vêm em função do habitus a ele incorporado, podendo, por exemplo, legitimar uma língua como natural. Ao posicionála como natural, coloca-se:

em jogo a acumulação de uma forma particular de capital, a honra no sentido de reputação, de prestígio, havendo, portanto, uma lógica específica da acumulação do capital simbólico, como capital fundado no conhecimento e no reconhecimento (BOURDIEU, 2004, p.35-36).

Daí, o Capital Cultural como o conhecimento, o reconhecimento de determinado saber legitimado socialmente, ou mesmo o desconhecimento desse saber. 
Desse modo, em relação à Língua Portuguesa e a Libras parecem operar essas ponderações em que:

o habitus, sistema de disposições adquiridas na relação com um determinado campo, torna-se eficiente" / "operante quando encontra as condições de sua eficácia, isto é, condições idênticas ou análogas àquelas de que ele é produto" (BOURDIEU, 2004, p. 130).

Assim, torna-se geradora de práticas ajustadas ao presente, no caso, na Língua Portuguesa como idioma e língua nacional, no padrão normativo. Ademais, esse habitus pode gerar padrões contraditórios, por exemplo, em relação a Libras, em práticas discursivas e representações que a classifica de forma subalterna em relação à língua dominante e majoritária - Língua Portuguesa, gerando a deslegitimação linguística da Língua de Sinais. Porém, outros padrões ou disposições adquiridas podem ser construídos, gerando a sua legitimação, marcando, assim, posições discursivas como posições assumidas pelo sujeito nas práticas sociais e internalizadas pelo habitus vivenciado, contudo, práticas e posições discursivas adquiridas em complexas e tensas relações de poder.

\section{De que competência linguística estamos falando?}

Essa relação de valoração atribuída à determinada língua, mas que de forma geral não ocorre em outras línguas, como de imigrantes, de grupos indígenas ou de comunidades surdas, por exemplo, atinge questões culturais, históricas e políticas; constitui o mercado linguístico e evidencia que as disposições dos sujeitos, o seu habitus, "as estruturas mentais através das quais eles apreendem o mundo social, são em essência produto da interiorização das estruturas do mundo social" (BOURDIEU, 2004, p.158.), podendo reproduzir assim estruturas de exclusão social, política e cultural da pessoa surda e negação de sua competência linguística, como no caso o bilinguismo surdo ${ }^{1}$, o que pode ser valorizado em outros casos de bilinguismo, desde que se mantenha em determinado campo linguístico. "Assim, enquanto o habitus e o campo estiverem afinados, o habitus "cai bem" e, à margem de qualquer cálculo, suas antecipações precedem a lógica do mundo objetivo (BOURDIEU, 2004, p. 131). Contudo:

${ }^{1}$ Bilinguismo surdo: uso da Língua natural ou materna, Língua Brasileira de sinais (L1), e da Língua Portuguesa (L2), podendo ser apenas na modalidade escrita. 
v. 7 (1)

421-433

jan/jun

2017

Para que um modo de expressão entre outros (uma língua, no caso do bilingüismo, uma utilização da língua, no caso de uma sociedade dividida em classes) se imponha como único legítimo, é preciso que o mercado lingüístico seja unificado e que os diferentes dialetos (classistas, regionais ou étnicos) estejam praticamente referidos à língua ou ao uso legítimo. Enquanto produto da dominação política incessantemente reproduzida por instituições capazes de impor o reconhecimento universal da língua dominante, a integração numa mesma "comunidade lingüística" constitui a condição da instauração de relações de dominação lingüística. (BOURDIEU, 2008, p.32).

Deve-se considerar que, para Bourdieu (2008), a língua oficial está vinculada ao Estado, portanto estabelece-se uma relação política em que se atribui valor dentro do mercado linguístico, a percepção dessa norma de valor que determina o que deve ou não ser dito, ou seja, o uso da língua pelo falante.

Tomando como referência a competência linguística como uma prática social, o saber socialmente construído em uso prático de interação e significação não seria algo inato ao sujeito, contrariamente ao inatismo proposto por Chomsky (1980). Nesse sentido, Morato e Bentes (2002, p.33) ponderam que a crítica que se faz em relação à prática social relacionada à competência (BOURDIEU, 2008) é concernente às "capacidades" e "ações reflexivas dos atores", mas que essas práticas seriam condicionadas "socioculturalmente". Assim, ainda segundo Morato e Bentes (2002), uma das principais propriedades da competência linguística para Bourdieu é a capacidade de reflexão. Para os autores, Bourdieu critica tanto Saussure em relação ao conceito de língua e estrutura, quanto Chomsky em relação à noção de competência inata ao sujeito que dela se apropria.

Depreende-se que o conceito de competência é bastante discutido na contemporaneidade e é necessário pontuar que a noção de competência linguística, muitas vezes, está atrelada à legitimidade ou deslegitimidade atribuída socialmente e politicamente à determinada língua, tida como padrão normativo, em relação de anulação e silenciamento de outras línguas, tidas como minoritárias, podendo relegar os seus falantes ao silêncioe e à exclusão sociocultural (do capital cultural e econômico).

É pertinente, então, compreender que a noção de competência linguística pode também significar "ver o outro como apto a construir aprendizagens relevantes para sua vida e participação na sociedade" (SCHALATTER; GARZEZ, 2009, p.127). Nesse direcionamento inteligência não é a "expressão de capacidades inatas, mas decorre do exercício de 
operações mentais, por meio das quais informações são transformadas para produzir conhecimentos" (SCHALATTER; GARZEZ, 2009, p.70), mediados pela linguagem enquanto processo de interação. Sendo assim, a competência linguística dos sujeitos surdos é decorrente das práticas sociais em que os sujeitos se inscrevem.

\section{Contexto, geração de dados e análise}

A coleta de dados ocorreu em 2016 por meio do mecanismo de busca Google, ferramenta de pesquisa, amplamente utilizada para indexar palavras-chave e buscar informações em documentos e bases de dados online. O mote de pesquisa: "pessoa surda", gerou aproximadamente 430.000 mil resultados em quarenta e dois segundos, mostrando a relevância do tema no contexto atual brasileiro. Daí, a necessidade de um recorte, especificamente, sobre discursos propagados nas redes sociais online sobre a pessoa surda e a língua de sinais.

Os dados foram gerados a partir do post: "Se uma pessoa nasce surda-muda, em qual língua ela pensa?", postado em 22 de setembro de 2010 no blog Chongas, um site de variedades, notícias e humor. Atualmente, além do blog, há um canal do youtuber Flávio Lamenza, com 2.539 seguidores e 1.848 publicações, e uma página, Chongas, no Facebook.

O post gerou 202 comentários. Desses, sete comentários serão analisados em duas categorias: deslegitimação da Libras vinculada à "deficiência" da pessoa surda e legitimação da Libras. Com essa escolha, pretende-se apresentar comentários que variam desde os que desconhecem a temática até os que a conhecem, abordando, desse modo, variações sobre o assunto.

Deslegitimação da Libras vinculada à "deficiência” da pessoa surda

Os excertos 1, 2 e 3 indicam como práticas discursivas podem contribuir para a reprodução da deslegitimação da Libras em discursos vinculados à "deficiência" da pessoa surda ao não uso da língua oral-auditiva, cujo conceito de linguagem, nos moldes tradicionais, é retomado para validar esse discurso.

1. Não é pq uma pessoa seja surda que ela nao possa falar!!! Va visitar uma escola para pessoas especiais, APAE, etc! (Grifos meus). (Fonte:www.chongas.com.br/2010/09/pergunto/). 
v. 7 (1)

421-433

jan/jun

2017
2. Concordo que se a pessoa é surda, ela não consegue ouvir, e portanto, não aprende a falar corretamente. Por isso se comunicam por sinais, dã. (Grifos meus).

(Fonte:www.chongas.com.br/2010/09/pergunto/)

Segundo o excerto 1, o surdo pode falar na modalidade oralauditiva (Língua Portuguesa), para isso é necessário ir a "uma escola para pessoas especiais, APAE" ou "etc", entendido aqui como instituições de tratamento. Da mesma forma, o posicionamento discursivo do excerto 2 associa à surdez à incapacidade "portanto não aprende a falar corretamente" conforme a modalidade oral da Língua Portuguesa.

No excerto a seguir, percebe-se uma inserção do sujeito surdo como deficiente, em que a pessoa surda assume esse discurso ao narrar sobre si mesma em relação à aquisição da linguagem.

3. Pessoal, eu sou surdo de nascença, mas isso não me impediu de aprender a falar, com a ajuda de fonoaudiologia, porém no começo eu falava muuuuito mal, pois ficava tentando falar igual aos outros, mas nem sabia o que de fato eles falavam. Eu uso aparelho auditivo desde os 5 anos, porém eu dependo essencialmente da leitura labial, que eu fui aprimorando com o tempo, pois o aparelho me permite identificar sons, mas não consigo distinguir os sons, para saber o que as pessoas estão falando tenho de fazer leitura labial. (...) não ligo para comentários que depreciem os deficientes físicos, (...) PS: Sim, eu penso em português.

(Fonte:www.chongas.com.br/2010/09/pergunto/).

(Grifos meu).

Conforme o excerto 3, a surdez é entendida como deficiência auditiva. Na primeira linha, o sujeito se identifica como surdo, o que se destaca com o uso do pronome "eu" e "isso". Contudo, o pronome "isso" é utilizado em referência ao fato de ser surdo, o que não o impediu de aprender "a falar corretamente", "com ajuda de fonoaudiologia" e com técnica de "leitura labial. Ao utilizar o advérbio "corretamente", indica uma valoração da modalidade oral da Língua Portuguesa, o que é confirmado, também na segunda linha, na declaração "ficava tentando falar igual aos outros", também do pronome "eles", na quarta linha. O comentário, ao que parece, é caracterizado por uma forma de 
reconhecimento do 'eu' surdo em relação aos 'outros', "eles" ouvintes, essa posição parece ser tomada como referência ao falar corretamente, que para o enunciador é o falar a língua legitimada socialmente. Também, estabelece referência a outros já-ditos (FOUCAULT, 2008), em que o surdo precisa "aprender a falar" a Língua Portuguesa. A questão aqui não é que ele, o surdo, precisa estabelecer uma comunicação ou interação com o outro, mas de estabelecer uma normalidade, pois há uma percepção que o 'normal' é ser ouvinte, pois ouvinte fala, 'aprende corretamente'. A concepção que se apresenta nos enunciados ainda parece ser a do surdo (a) como deficiente.

Percebe-se, nos excertos 1, 2 e 3, uma deslegitimação da Libras que sequer é considerada como língua natural dos surdos, apesar da Lei $n^{\circ} 10.436$ garantir essa legitimidade. No excerto 2, nega-se essa legitimidade, ao enunciar que a comunicação em "sinais" não se configura como um "falar corretamente", o que só seria possível a quem "consegue ouvir, e portanto" "falar corretamente", sendo que "se a pessoa é surda, ela não consegue ouvir, e portanto, não aprende a falar corretamente. Por isso se comunicam por sinais, dã". Essa prática discursiva parece ser embasada na competência linguística para falar a língua legítima (BOURDIEU, 2008, p. 42).

\section{A legitimação da Libras}

A competência linguística dos surdos como fator de legitimação da Libras parece estar embasada no capital cultural dos enunciadores. Nos excertos 4 e 5, por exemplo, a questão do Capital Cultural dos enunciadores é exemplificado a seguir:

4. A resposta é simples, e a pergunta revela uma certa ignorância tupiniquim. Primeiro, Pessoas Surdas (assim mesmo, com $\mathbf{S}$ maiúsculo) não são necessariamente mudas (assim mesmo, com m minúsculo). Por que? Pesquisem.

Segundo, elas se comunica e, portanto, pensa em LIBRAS (Língua - e não linguagem - Brasileira de Sinais). 0 que é isso? Pesquisem.

(Fonte: www.chongas.com.br/2010/09/pergunto/). (Grifos meu).

5. Ainda bem que eu nem precisei repetir. Ia repetir o que 
v. 7 (1)

421-433

jan/jun

2017

o (F. excerto acima) disse. A LIBRAS existe. Faço parte da comunidade surda, sou monitor da disciplina de LIBRAS na universidade onde estudo.

(Fonte: WwW.chongas.com.br/2010/09/pergunto/). (Grifos meu).

Os excertos 4 e 5 evidenciam também o capital linguístico dos enunciadores, os que detêm o saber necessário sobre o assunto. Como exemplo, o excerto 4, que, ao enumerar uma explicação - "primeiro" e "segundo" - e nas perguntas "Por que?" e "O que é isso?" seguido da resposta "Pesquisem" aponta para um conhecimento adquirido (Capital Cultural) do falante. Também, no excerto 5, a posição discursiva assumida pelo falante "faço parte da comunidade surda", "sou monitor da disciplina de LIBRAS" e a menção à instituição superior de ensino "universidade", corrobora a significação da pessoa desinencial (eu) "estudo" que indica o Capital Cultural e a posição do enunciador.

Nos excertos 6 e 7, a Legitimação da Libras e a Competência linguística dos surdos nos enunciados são descritos a seguir:

6. Não meu caro amigo, a língua de sinais não é um padrão que pode ser adaptado a qualquer língua. Se fosse assim, você teria que admitir que uma pessoa surda teria que primeiro aprender o português (ou outra língua) para depois aprender a se comunicar em sinais. Pesquisas mostram que uma criança surda passa pelos mesmos estágios de aquisição de linguagem que uma criança ouvinte, a língua que ela aprende vai depender do imput (estímulo) a que ela é exposta. Sendo assim, é fácil raciocinar que uma criança surda NÃO recebe estímulos da língua portuguesa então não pode adquirir essa língua de forma natural. Caso ela seja filha de pais surdos, vai aprender a língua de sinais passando pelos mesmos estágios que uma criança ouvinte, pelo contrário, se for filha de pais ouvintes temos um problema para o desenvolvimento cognitivo desta criança, pois o período crítico para a aquisição de uma língua vai até mais ou menos os 4 anos de idade! e ela não vai aprender português como nós aprendemos, fato! (Fonte: www.chongas.com.br/2010/09/pergunto/). (Grifos meu). 
7. "Você pensa no idioma que foi alfabetizado."

Então analfabetos não pensam? Fala sério, resposta nada a ver.

A criança ouvinte aprende a partir dos sons emitidos pelos adultos, a criança surda, que possui a mesma capacidade de aprendizado, vai aprender os gestos e se comunicar por eles, e futuramente vai poder aprender a LIBRAS - Língua Brasileira de Sinais, idioma oficial dos surdos brasileiros. (Sim, não é português com as mãos, é outra língua).

(Fonte: www.chongas.com.br/2010/09/pergunto/). (Grifos meu).

O excerto 6, busca desmistificar o mito da Língua de Sinais como padrão único universal ou mímicas utilizadas pelos surdos, o que é confirmado na proposição "a língua de sinais não é um padrão que pode ser adaptado a qualquer língua".

A questão da competência linguística das pessoas surdas, usuários da Libras, parece ser abordada, tanto no comentário 6 "criança surda passa pelos mesmos estágios de aquisição de linguagem que uma criança ouvinte", quanto no comentário 7 a "criança surda vai aprender", "vai poder aprender" da mesma forma que a "criança ouvinte". Porém, aponta que a diferença não está na competência linguística da criança ou do falante, mas na estrutura linguística, uma vez que a "criança ouvinte aprende a partir dos sons emitidos pelos adultos", na modalidade oral-auditiva Língua Portuguesa, no entanto, a criança surda "vai aprender os gestos e se comunicar por eles", no caso a modalidade gestual-visual - Libras.

O excerto 7 marca discursivamente "a LIBRAS-Língua Brasileira de Sinais" como "idioma oficial dos surdos brasileiros". A palavra idioma está vinculada à língua oficial de um país, não é apenas uma língua com seu conjunto de regras gramaticais e linguísticas, mas se estabelece como referencial a um povo. Pode-se inferir que, ao mobilizar a palavra idioma em detrimento de língua, como é comumente utilizado, pretende estabelecer politicamente uma possível equiparação entre as línguas faladas no Brasil, buscando evocar uma relação menos assimétrica entre ouvinte e surdo. Esse sentido parece se reafirmar no enunciado "Sim, não é português com as mãos, é outra língua". A justificativa é que a surdez não impede a aprendizagem, desde que a criança tenha acesso ao aprendizado no estágio cognitivo adequado e de forma adequada.

Os excertos 6 e 7, apresentam um esclarecimento da estrutura linguística da Língua de Sinais. Também, evidencia que o habitus 
v. 7 (1)

421-433

jan/jun

2017

dos enunciadores possibilita o lócus das enunciações, sendo que os enunciadores buscam, a partir do seu capital cultural, desconstruir a deslegitimação e afirmar a legitimação e a competência linguística dos surdos, como na asserção: "Pesquisas mostram que uma criança surda passa pelos mesmos estágios de aquisição de linguagem que uma criança ouvinte, a língua que ela aprende vai depender do input (estímulo) a que ela é exposta".

As palavras "desenvolvimento", "cognitivo", "aquisição", "input" e "aprendemos" evidenciam o saber que se efetiva em pesquisas, concordando que o saber científico é um "fato!" não uma suposição, contestando assim, os comentários dos excertos 1, 2 e 3.

Diante dessas asserções, conclui-se que os excertos 4, 5, 6 e 7 inserem a Libras dentro de um discurso que a legitimam como língua natural da pessoa surda. Daí, a competência linguística está atrelada ao estímulo adequado e interação dos usuários em práticas significativas e não às capacidades cognitivas inatas ao sujeito.

\section{Considerações Finais}

As condições socioculturais e materiais parecem determinar simbolicamente as diferenças entre os grupos, o que ocorre algumas vezes com os sujeitos surdos tidos como deficientes ou anormais em relação a determinado padrão social essencialista e hegemônico. Essas representações parecem ditar como o "sujeito surdo deve narrar-se e olhar-se nos moldes ouvintistas" (SKLIAR, 2005, p. 15).

Desse modo, o reconhecimento da Libras como língua legítima nas práticas sociais pode permitir que o surdo, ao invés de ser percebido como deficiente, portador de uma patologia ou sujeito desprovido de uma competência linguística, possa ser percebido dentro de um viés mais social e cultural, podendo assim comunicar-se na Língua de Sinais, reconhecida como língua natural do surdo, ou, se assim o desejar, na Língua Portuguesa, sem que essa escolha lhe seja imposta como padrão de normalidade e inclusão social, visto que "as diferenças" na contemporaneidade fazem parte da diversidade social e cultural inerente à sociedade.

Em razão dessa discussão, a perspectiva de Bourdieu é relevante para compreender como o habitus pode ser incorporado pelo sujeito, orientando determinados posicionamentos discursivos, que ora silenciam a Libras como língua legítima da comunidade surda do Brasil, podendo relegar os seus "falantes" ou sinalizantes à condição de exclusão social e 
negar-lhes a competência linguística, ora de maneira contrária defendem a legitimação da Libras e a competência linguística dos surdos, utilizando o Capital Cultural a partir da construção de um novo habitus, partindo de um conjunto de vivências e práticas que possam subsidiar novos enunciados, apontando para novas posições discursivas a serem ocupadas pelos sujeitos. Destaque-se, todavia, que essas práticas discursivas não são neutras, mas permeadas por relações de poder.

\section{Referências}

BOURDIEU, P. A Economia das Trocas Linguísticas: 0 que Falar Quer Dizer. Prefácio e Tradução Sergio Miceli - 2. ed. São Paulo: Editora da Universidade de São Paulo, 2008.

Coisas Ditas. Tradução Cássia R. da Silveira e Denise Moreno Pegorim. São Paulo: Brasiliense, 2004.

CHOMSKY, N. Estruturas sintáticas, Lisboa: Edições 70, 1980.

FOUCAULT, M. A arqueologia do saber. Tradução Luiz Felipe Baeta Neves. Rio de Janeiro: Forense Universitária, 8. ed. 2008.

MAZZOTA, M. Educação especial no Brasil: histórias e políticas públicas. 6 . ed. São Paulo: Cortez, 2011.

MORATO, E.; BENTES, A. Das intervenções de Bourdieu no campo da linguística: reflexões sobre competência e língua legítima. Horizontes, Bragança Paulista, v. 20, p. 31-48, jan./dez. 2002.

NOGUEIRA, C.; NOGUEIRA. M. A. A Sociologia da Educação de Pierre Bourdieu: Limites e Contribuições. In: Educação \& Sociedade, ano XXIII, no 78, Abril/2002.

PERLIN, G.; STROBEL, K. História cultural dos surdos: desafio contemporâneo. Educar em Revista, Curitiba: Editora UFPR, Edição Especial n. 2/2014, p. 17-31.

QUADROS, R. M. de (Org.). Estudos surdos III. Petrópolis, RJ: Arara Azul, 2008.

SAUSSURE, F. de. Curso de Linguística Geral. Tradução Antônio Chelini, José Paulo Paes, Isidoro Blikstein. 27. ed. São Paulo: Cultrix, 2006.

SCHLATTER, M; GARCEZ, P. M. Línguas adicionais (Espanhol e Inglês). In: Rio Grande do Sul, Secretaria de Estado de Educação, Departamento Pedagógico (Org.). Referencial Curricular do Estado do Rio Grande do Sul: linguagens, códigos e suas tecnologias. Porto Alegre: Secretaria de Estado de Educação, Departamento Pedagógico, 2009, v.1, p. 127-172.

SKLIAR, C. Um olhar sobre o nosso olhar acerca da surdez e as diferenças. In: Carlos Skliar (Org.). A surdez: um olhar sobre as diferenças. 3. ed. Porto Alegre: Mediação, 2005, p. 07-32. 